\title{
Balancing surface area with electron recombination in nanowire-based dye-sensitized solar cells
}

\author{
Luping Li, ${ }^{1 *}$ Cheng Xu, ${ }^{1,2}$ Yang Zhao, ${ }^{1}$ and Kirk J. Ziegler ${ }^{1,2^{*}}$ \\ ${ }^{1}$ Department of Chemical Engineering, University of Florida, Gainesville, Florida 32611 \\ ${ }^{2}$ Department of Materials Science \& Engineering, University of Florida, Gainesville, \\ Florida 32611 \\ *Corresponding author. Email address: kziegler@che.ufl.edu (K. Ziegler), \\ lupingli@ufl.edu (L. Li)
}

\begin{abstract}
Dye-sensitized solar cells (DSSCs) represent a promising technology in the renewable energy portfolio. In this study, tin-doped-indium oxide (ITO) nanowires are used to prepare DSSC photoanodes that overcome charge transport limitations associated with conventional nanoparticle-based photoanodes. Vertically-aligned ITO nanowires are grown by a thermal evaporation method and a porous $\mathrm{TiO}_{2}$ shell layer is uniformly coated on the nanowire surfaces to ensure high dye-loading. It is found that cell efficiency increased to $4.85 \%$ from $2.81 \%$ when a dense $\mathrm{HfO}_{2}$ blocking layer is inserted between ITO nanowire surfaces and the porous $\mathrm{TiO}_{2}$ shell. While more photoactive surface area associated with longer nanowires improves device performance, nanowires longer than $20 \mu \mathrm{m}$ show reduced efficiency from an increase in electron recombination. Therefore, $20-\mu \mathrm{m}$-long nanowires show the best efficiency, which is attributed to the balance of surface area and electron recombination in the photoanode. Although decreasing $\mathrm{TiO}_{2}$ annealing temperatures from 600 to $400{ }^{\circ} \mathrm{C}$ increases electron recombination, the smaller $\mathrm{TiO}_{2}$ nanoparticles at $400{ }^{\circ} \mathrm{C}$ lead to much higher dye-loading and, ultimately, the highest device efficiency of $5.59 \%$.
\end{abstract}

Keywords: dye-sensitized solar cell; nanowire; tin doped indium oxide; surface area; electron recombination 


\section{Introduction}

Dye-sensitized solar cells (DSSCs) represent a reliable and affordable renewable energy technology and they have garnered a lot of attention in the scientific community.[1-5] The photoanode of a DSSC typically consists of a nanoparticle-based $\mathrm{TiO}_{2}$ thin film ( 10 $\mu \mathrm{m}$ in thickness) deposited on a transparent conductive oxide (TCO). In the $\mathrm{TiO}_{2}$ nanoparticles, charge transport is generally dictated by a multiple trapping/detrapping process, where electrons in the conduction band fall into the shallow traps (sub-bandgap states) and are then detrapped through thermal vibration.[6] The rate of charge transport in $\mathrm{TiO}_{2}$ nanoparticles is $2-3$ orders of magnitude slower than in bulk $\mathrm{TiO}_{2}$ due to the many defects and grain boundaries in $\mathrm{TiO}_{2}$ nanoparticles.[7, 8] The slow charge transport in $\mathrm{TiO}_{2}$ nanoparticles makes electrons susceptible to recombination, which results in major electron loss and is one of the limiting factors on DSSC performance.[9]

One strategy to reducing electron recombination is to insert blocking layers at the interfaces of the photoanode. For instance, $\mathrm{HfO}_{2}$ blocking layers were coated onto $\mathrm{TiO}_{2}$ nanoparticle surfaces by a sol-gel method and DSSC efficiency was improved by 69\%.[10] Palomeres et al. [11] investigated the effectiveness of $\mathrm{SiO}_{2}, \mathrm{Al}_{2} \mathrm{O}_{3}$, and $\mathrm{ZrO}_{2}$ blocking layers, where $\mathrm{Al}_{2} \mathrm{O}_{3}$ showed the greatest efficiency enhancement (35\%) due to its high point-of-zero-charge. The improvements in efficiency have been attributed to the blocking layers passivating the surface states in the photoanode.[12,13] To achieve the best results, the blocking layer should be thin and compact. Compact blocking layers establish a physical separation between the photoanode and the electrolyte, which reduces the probability of electrons travelling back to the electrolyte. Thinner blocking layers (less than a few nanometers) allow most of the passing electrons to tunnel through, thus maximizing the current flow. 
Alternatively, increasing the rate of charge transport in the photoanode reduces the probability of electron recombination and consequently enhances DSSC efficiency. Using nanowires as the photoanode is an effective approach to increase the rate of charge transport due to the presence of an interfacial electric field within the nanowires that is not present in nanoparticles.[14-16] Hill et al.[14] showed that photoanodes fabricated from core-shell nanowires resulted in the injected electrons within the semiconductor shell layer being quickly swept into the core by the radial electrical field in the shell. The benefits of reducing trap-limited electron transport may be especially beneficial at high illumination conditions.[15] Using photomodulation techniques, Martinson et al.[16] revealed that electron transport is tens to thousands of times faster in $\mathrm{ZnO}$ nanowire-based DSSCs than in nanoparticles. Noh et al.[17] obtained similar results in ITO nanowire-based DSSCs.

Annealing the $\mathrm{TiO}_{2}$ layer is usually required to achieve high device efficiency. Mohammadpour et al.[18] fabricated $\mathrm{TiO}_{2}$ nanotubes by anodization and annealed the structures at temperatures between 400 and $800^{\circ} \mathrm{C}$. The highest efficiency was reached at $600{ }^{\circ} \mathrm{C}$ due to remarkably fast charge transport at $600{ }^{\circ} \mathrm{C}$. Higher annealing temperatures resulted in lower dye loading. On the other hand, Atta et al.[19] reported lower efficiency at similar $\mathrm{TiO}_{2}$ annealing temperatures between 450 and $650{ }^{\circ} \mathrm{C}$, which was attributed to the larger pore size and higher surface area for $\mathrm{TiO}_{2}$ structures annealed at $450^{\circ} \mathrm{C}$.

Depending on the photoanode structure, the primary electron recombination pathways may be from $\mathrm{TiO}_{2}$ to the electrolyte $\left(1 / l_{3}{ }^{-}\right)$or from TCO to the electrolyte. In $\mathrm{TiO}_{2}$-nanoparticle-based DSSCs, electron recombination from $\mathrm{TiO}_{2}$ to the electrolyte may dominate due to the slow electron transport in $\mathrm{TiO}_{2}$ nanoparticles. Consequently, most existing studies focused on inserting various blocking layers on $\mathrm{TiO}_{2}$ in 
nanoparticle-based DSSCs.[10-12] In nanowire-based DSSCs, electron recombination from $\mathrm{TiO}_{2}$ to the electrolyte is greatly alleviated due to the rapid charge transport from $\mathrm{TiO}_{2}$ to the nanowires. On the other hand, electron recombination from TCO (nanowires) to the electrolyte is exacerbated because of the dramatically higher surface area of the nanowires that are exposed to the electrolyte.

In this study, $\mathrm{HfO}_{2}$ blocking layers are inserted by atomic layer deposition (ALD) to reduce electron recombination in ITO nanowire-based DSSCs. The balance of higher surface area and lower electron recombination is investigated for different nanowire length and $\mathrm{TiO}_{2}$ annealing temperatures, which lead to the highest device efficiency of $5.59 \%$.

\section{Fabrication and characterization of DSSCs}

\subsection{ITO nanowire synthesis}

ITO nanowires are synthesized following our previous work.[20] Briefly, transparent ITO/glass (Thin Film Devices, USA) substrates were consecutively cleaned in deionized water, acetone, and ethanol using ultrasonication. A 3-nm Au film was deposited on ITO as the catalyst for nanowire growth. High-purity metallic powders of indium (99.99\%) and tin $(99.995 \%)$ were mixed with a spatula in an atomic ratio of $10: 4.5$. The mixed powder was put in a quartz boat and loaded in the middle of a quartz tube furnace. The substrate was placed a few centimeters downstream from the powder. A stream of $0.5 \%$ $\mathrm{O}_{2}$ (balance $\mathrm{Ar}$ ) was fed through the tube at a flow rate of $40 \mathrm{sccm}$ and the furnace was rapidly heated to $750^{\circ} \mathrm{C}$. A vacuum pump was used to maintain a vacuum level below 0.3 Torr. 


\subsection{Photoanode preparation}

A thin layer of $\mathrm{HfO}_{2}$ was deposited onto the ITO nanowire surfaces via ALD (Cambridge Nano Fiji 200). Water and tetrakis (dimethylamido) hafnium (IV) were used as the $\mathrm{O}$ and $\mathrm{Hf}$ source, respectively. A total of 16 ALD cycles were performed. Subsequently, a porous $\mathrm{TiO}_{2}$ shell was coated on the nanowires by $\mathrm{TiCl}_{4}$ treatment. To prepare the $\mathrm{TiCl}_{4}$ coating solution, a $4.7 \mathrm{M} \mathrm{TiCl}_{4}$ stock solution was first prepared by placing ice cubes quickly into refrigerated $\mathrm{TiCl}_{4}$ (caution: this reaction is vigorous and should be done in the fume hood while wearing adequate personal protective equipment). The thick, yellowish stock solution can be stored in a refrigerator indefinitely. The stock solution was diluted to $0.1 \mathrm{M}$ and nanowires were immersed for 8 hours at room temperature. This coating process was repeated 12 times for all nanowire samples. After coating, nanowires were annealed between 400 and $600{ }^{\circ} \mathrm{C}$ for $1 \mathrm{~h}$ in air.

\subsection{DSSC cell fabrication}

N719 dye (Dyesol, Australia) was dissolved in ethanol to give a concentration of 3 $\mathrm{mM}$. $\mathrm{TiO}_{2}$-coated ITO nanowires were immersed in the dye solution for $\sim 12 \mathrm{~h}$ and used as the photoanode. A counter-electrode solution (CELS, Dyesol) was spin-coated onto clean ITO/glass and annealed at $430^{\circ} \mathrm{C}$ for $10 \mathrm{~min}$. Scotch tape was used as the spacer and an iodine-based solution (EL-HPE, Dyesol) was used as the electrolyte. A schematic of the cell is shown in Scheme 1.

\subsection{Characterization}

An X'Pert Powder XRD (PANalytical, USA) was used to collect the XRD spectra of ITO nanowires. SEM images were obtained using a FEI Nova NanoSEM 430. TEM imaging was performed on a JEOL 2010F TEM. To measure cell efficiency, a light source (XPS 200 coupled with 16S, Solar Light Company, USA) was used to produce a 
global AM 1.5 spectrum with a power density of $100 \mathrm{~mW} \cdot \mathrm{cm}^{-2}$. Before cell testing, the light intensity was calibrated by a Si reference cell (RCSi65, PV Measurements, USA). Current-voltage characteristics were recorded by a potentiostat (VersaSTAT 3, Princeton Applied Research, USA). A two-terminal setup was established by combining the working/sensing electrodes and the reference/counter electrodes. DSSC cells were illuminated through a black aperture with an area of $0.08 \mathrm{~cm}^{2}$. For each type of cell 3-4 devices were tested. The reported cell performance statistics was determined by Pierce's criterion. Open-circuit voltage decay (OCVD) curves were recorded with the same potentiostat. During OCVD measurement, cells were illuminated and the opencircuit voltage was monitored. Illumination was then interrupted and the transient voltage was recorded at dark. Dye loading of the photoanodes was determined by a UV-vis spectrometer (Perkin-Elmer Lambda 800). The photoanodes were submerged in a $0.1 \mathrm{M}$ $\mathrm{NaOH}$ water/ethanol $(1: 1 \mathrm{v} / \mathrm{v})$ solution for $2 \mathrm{~h}$ for the dye to desorb. Dye solutions of known concentrations were prepared in the same solvents. The UV-vis spectra are included in Supporting Information.

\section{Results and discussion}

\subsection{ITO nanowires}

Figure 1a shows a typical SEM image of the as-grown ITO nanowires on a ITO/glass substrate. The diameters of the nanowires were 100-200 nm and their lengths can be controlled by the growth time. Most of the nanowires were vertically aligned, which could provide direct pathways for charge collection during DSSC operation. Figure $1 \mathrm{~b}$ is the XRD pattern for ITO nanowires. These nanowires can be indexed to an $\ln _{2} \mathrm{O}_{3}$ cubic structure (bixbyite) with a JCPDS \# 06-0416. The strongest (400) peak indicates that the growth direction of ITO nanowires is along [100]. 


\subsection{Different nanowire lengths}

ITO nanowires with lengths between 10 and $28 \mu \mathrm{m}$ were coated with a thin $\mathrm{HfO}_{2}$ blocking layer by ALD. During ALD, nanowires were alternately exposed to $\mathrm{Hf}$ and $\mathrm{O}$ precursors, which were separated by an Ar purging step. ALD boasts excellent coating uniformity on high aspect-ratio nanostructures. The same coating thickness and quality from nanowire top to bottom were observed. The nanowires were subsequently coated with a porous $\mathrm{TiO}_{2}$ shell via $\mathrm{TiCl}_{4}$ treatment. All $\mathrm{TiO}_{2}$ shells were annealed at $500{ }^{\circ} \mathrm{C}$ in air. Figure $2 \mathrm{a}$ and $\mathrm{b}$ are TEM images of ITO nanowires before and after the deposition of $\mathrm{HfO}_{2}$ blocking layer, respectively. The $\mathrm{HfO}_{2}$ blocking layer has a thickness of $\sim 1.3 \mathrm{~nm}$ after depositing 16 ALD cycles. Compact and thin blocking layers, such as the one shown in b, are advantageous in reducing electron recombination in DSSCs. Figure 2c shows a TEM image of a nanowire coated with a porous $\mathrm{TiO}_{2}$ shell. The $\mathrm{TiO}_{2}$ shell uniformly covered nanowire surfaces, which provides maximum surface area for dye attachment.

Figure 3 shows the current-voltage response of DSSCs fabricated using nanowires of different lengths. Their photovoltaic properties are summarized in Table 1. It is seen that, for 20- $\mu \mathrm{m}$ nanowires, both the short-circuit current $\left(\mathrm{J}_{\mathrm{sc}}\right)$ and the open-circuit voltage $\left(\mathrm{V}_{\text {oc }}\right)$ increased dramatically upon deposition of $1.3 \mathrm{~nm}$ of $\mathrm{HfO}_{2}$. Consequently, cell efficiency increased from $2.81 \%$ to $4.85 \%$. The increase in $\mathrm{J}_{\mathrm{sc}}$ is attributed to the reduction of electron recombination by $\mathrm{HfO}_{2}$ from ITO nanowire surfaces to the electrolyte. The reduced electron recombination is also evidenced by lower dark current upon $\mathrm{HfO}_{2}$ deposition (Figure 3b). Electron transport from the $\mathrm{TiO}_{2}$ shell to the ITO core is not expected to be impacted since most electrons can tunnel through the thin $\mathrm{HfO}_{2}$ layer.[4, 5, 9] The $\mathrm{V}_{\text {oc }}$ of a DSSC is determined by the difference between the Fermi level of the $\mathrm{TiO}_{2}$ and the Fermi level of the redox couple in the electrolyte. The increase in $\mathrm{V}_{\mathrm{oc}}$ 
seen in Figure 3a may result from the reduction of electron recombination, which could increase the Fermi level of the $\mathrm{TiO}_{2}$.

In Figure 3a, as nanowire length increased from 10 to $28 \mu \mathrm{m}$, the efficiency first increased to $4.85 \%$ for $20-\mu \mathrm{m}$ nanowires and then decreased slightly. The initial increase is due to the the increase of active surface area in nanowires, which enabled higher dye loading and, in turn, higher current density (Table 1). When nanowire length is further increased to $28 \mu \mathrm{m}$, dye loading and current density continue to increase. However, an increase in electron recombination led to lower efficiency. This is witnessed by the higher dark current seen in Figure $3 b$. The higher dark current for longer nanowires is likely due to electrolyte transport issues. Due to the confinement of electrolyte between nanowires, the increased length of the photoanode causes dye regeneration problems that lead to electron loss (REF Hill Thesis).

Figure 4a shows the open-circuit voltage decay (OCVD) curves of DSSCs fabricated with nanowires of different length. The $20-\mu \mathrm{m}$ nanowires showed the slowest decay, which indicates that these nanowires can retain the highest concentration of electrons. Electron lifetime $\left(\tau_{\mathrm{n}}\right)$ can be determined from the OCVD curves using the expression $\tau_{\mathrm{n}}=\left(-k_{B} T / e\right)\left(d V_{o c} / d t\right)^{-1}$, [21] where $k_{B}$ is the Boltzmann constant, $T$ is the absolute temperature, and $e$ is the positive electron charge. The results are shown in Figure $4 \mathrm{~b}$. It is seen that the $20-\mu \mathrm{m}$ nanowires have the longest electron lifetime. Because there is no current flux during OCVD measurements, the differences in electron lifetime may be associated with the different charge distribution within different components of the photoanode $\left(\mathrm{TiO}_{2}\right.$, ITO nanowires, and the substrate). Different components have different charge recombination rates,[20] which results in differences in the observed voltage decay and hence the electron lifetime. The long electron lifetime for $20-\mu \mathrm{m}$ nanowires contributed to their best efficiency, as seen in Table 1. 
Although electron lifetime was calculated using the expression $\tau_{\mathrm{n}}=\left(-k_{B} T / e\right)\left(d V_{o c} / d t\right)^{-1}$,[19] a long electron lifetime may not necessarily correspond to a high $\mathrm{V}_{\text {oc }}$ during $\mathrm{J}-\mathrm{V}$ measurement. This is because the $\mathrm{V}_{\mathrm{oc}}$ in the above expression is a transient voltage that is monitored after illumination has been interrupted. Therefore, it is a "dark" voltage. On the other hand, the $\mathrm{V}_{\text {oc }}$ during $\mathrm{J}-\mathrm{V}$ measurement (Figure $3 \mathrm{a}$ ) is the open-circuit voltage under continuous illumination. Therefore, both electron lifetime and open-circuit voltage are important characteristics of a DSSC.

\subsection{Different $\mathrm{TiO}_{2}$ annealing temperatures}

Cell efficiency is optimized using different $\mathrm{TiO}_{2}$ annealing temperatures. A $1.3 \mathrm{~nm}$

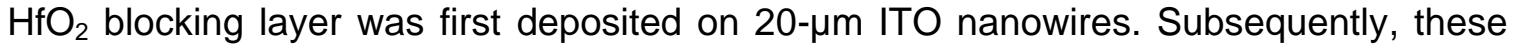
nanowires were identically coated with a porous $\mathrm{TiO}_{2}$ shell by $\mathrm{TiCl}_{4}$ treatment. The $\mathrm{TiO}_{2}$ shell was annealed at temperatures between 400 and $600{ }^{\circ} \mathrm{C}$ in air. Figure 5 shows TEM images of the porous $\mathrm{TiO}_{2}$ shell annealed at different temperatures. It is seen that the thickness of the $\mathrm{TiO}_{2}$ shell is $\sim 70 \mathrm{~nm}$ and the size of $\mathrm{TiO}_{2}$ nanoparticles increased with increasing annealing temperatures.

Figure 6 shows the current-voltage response of cells when $\mathrm{TiO}_{2}$ was annealed between 400 and $600{ }^{\circ} \mathrm{C}$. Their photovoltaic properties are listed in Table 2. It is seen that the $\mathrm{J}_{\mathrm{sc}}$ increased with decreased annealing temperatures. This response is partly attributed to higher dye-loading at lower $\mathrm{TiO}_{2}$ annealing temperatures, as seen in Table 2. Lower annealing temperatures led to $\mathrm{smaller}^{\mathrm{TiO}_{2}}$ nanoparticles (Figure 5), which provides larger surface area for dye attachment. Similarly, Han et al.[21] investigated ITO nanowire-based DSSCs and reported increased efficiency despite higher dark current when $\mathrm{TiO}_{2}$ annealing temperatures decreased from 600 to $500{ }^{\circ} \mathrm{C}$. Their efficiency increase was also attributed to higher dye loading at $500{ }^{\circ} \mathrm{C}$. 
Each of the devices exhibited similar $\mathrm{V}_{\text {oc }}$ even though the $\mathrm{TiO}_{2}$ was annealed at different temperatures. The similarity in $\mathrm{V}_{\mathrm{oc}}$ is attributed to the identical $\mathrm{HfO}_{2}$ blocking layers deposited on the nanowire surfaces of each photoanode. The identical blocking layers would be expected to induce similar Fermi levels in the $\mathrm{TiO}_{2}$ layer of each photoanode, even when annealed at different temperatures. The similarity in the blocking layers across different photoanodes result in the same shunt resistance for each device. When similar $V_{\text {oc }}$ is observed between DSSCs, the dark current would typically be expected to have similar magnitude. This relationship is because the Fermi level of the $\mathrm{TiO}_{2}$, which determines $\mathrm{V}_{\mathrm{oc}}$, also dictates the energy barrier during dark current flow. However, different dark current is observed in Fig. 6b, with lower annealing temperatures resulting in a higher magnitude of dark current. This relationship between $\mathrm{V}_{\mathrm{oc}}$ and dark current assumes that there are no changes to contact area. The higher porosity within the $\mathrm{TiO}_{2}$ shell when annealed at lower temperatures is expected to cause more intimate contact between the nanowire and the electrolyte. The higher contact area increases the probability of electron recombination, resulting in the higher dark current. However, the higher dye-loading led to higher current density, counteracting the negative effects from increased electron recombination, ultimately leading to higher device efficiency at lower annealing temperatures.

\section{Conclusions}

ITO nanowire-based DSSCs were fabricated to overcome the electron-transport limitations of conventional nanoparticle-based DSSCs. Although the core-shell nanowires have a radial electric field, the high surface area of ITO exposed to the electrolyte still caused significant electron recombination. Therefore, nanowire surfaces were deposited with a thin $\mathrm{HfO}_{2}$ blocking layer by ALD to reduce electron recombination. A porous $\mathrm{TiO}_{2}$ shell was subsequently coated onto the nanowire surface to ensure high 
dye-loading. It was found that the $\mathrm{HfO}_{2}$ blocking layer increased cell efficiency from 2.81 to $4.85 \%$. Cell efficiency was further optimized by using nanowires of different lengths and annealing the $\mathrm{TiO}_{2}$ shell at different temperatures. The $20-\mu \mathrm{m}$ nanowires showed the highest efficiency because they have the longest electron lifetime, as shown by OCVD measurement. When $\mathrm{TiO}_{2}$ annealing temperatures are decreased from 600 to $400{ }^{\circ} \mathrm{C}$, the short-circuit current increased while the open-circuit voltage remained the same, leading to the highest device efficiency of $5.59 \%$.

\section{Acknowledgements}

The authors acknowledge the support of the Donors of the American Chemical Society Petroleum Research Fund, the University of Florida Opportunity Fund, and the National Science Foundation (CBET-1033736) for support of this research.

\section{Supporting Information}

The UV-vis spectra of the photoanodes are included in Supporting Information. 


\section{References}

[1] B.E. Hardin, H.J. Snaith, M.D. McGehee, Nat. Photonics, 6 (2012) 162-169.

[2] M. Ye, X. Wen, M. Wang, J. locozzia, N. Zhang, C. Lin, Z. Lin, Mater. Today, (2014).

[3] A. Hagfeldt, G. Boschloo, L. Sun, L. Kloo, H. Pettersson, Chem. Rev., 110 (2010) 6595-6663.

[4] L. Li, S. Chen, C. Xu, Y. Zhao, N.G. Rudawski, K.J. Ziegler, ACS Appl. Mater. \& Interfaces, 6 (2014) 20978-20984.

[5] L. Li, C. Xu, Y. Zhao, K.J. Ziegler, Adv. Cond. Matter Phys., vol. 2014 Article ID 903294, 6 pages, 2014. doi:10.1155/2014/903294.

[6] H. Wang, M. Liu, M. Zhang, P. Wang, H. Miura, Y. Cheng, J. Bell, Phys. Chem. Chem. Phys., 13 (2011) 17359-17366.

[7] A.C. Fisher, L.M. Peter, E.A. Ponomarev, A.B. Walker, K.G.U. Wijayantha, J. Phys. Chem. B, 104 (2000) 949-958.

[8] M. Law, L.E. Greene, J.C. Johnson, R. Saykally, P. Yang, Nat. Mater., 4 (2005) 455459.

[9] A.K. Chandiran, M.K. Nazeeruddin, M. Grätzel, Adv. Funct. Mater., 24 (2014) 16151623.

[10] P. Ramasamy, M.-S. Kang, H.-J. Cha, J. Kim, Mater.Res. Bull., 48 (2013) 79-83.

[11] E. Palomares, J.N. Clifford, S.A. Haque, T. Lutz, J.R. Durrant, J. Am. Chem.Soc., 125 (2002) 475-482.

[12] T.C. Li, M.S. Góes, F. Fabregat-Santiago, J. Bisquert, P.R. Bueno, C. Prasittichai, J.T. Hupp, T.J. Marks, J. Phys. Chem. C, 113 (2009) 18385-18390.

[13] C. Prasittichai, J.T. Hupp, J. Phys. Chem. Lett., 1 (2010) 1611-1615.

[14] J.J. Hill, N. Banks, K. Haller, M.E. Orazem, K.J. Ziegler, J. Am. Chem.Soc., 133 (2011) 18663-18672.

[15] A. Du Pasquier, H. Chen, Y. Lu, Appl. Phys. Lett., 89 (2006) 253513.

[16] A.B. Martinson, J.E. McGarrah, M.O. Parpia, J.T. Hupp, Phys. Chem. Chem. Phys. 8 (2006) 4655-4659.

[17] J.H. Noh, H.S. Han, S. Lee, J.Y. Kim, K.S. Hong, G.S. Han, H. Shin, H.S. Jung, Adv. Energy Mater., 1 (2011) 829-835.

[18] F. Mohammadpour, M. Altomare, S. So, K. Lee, M. Mokhtar, A. Alshehri, S. A. AlThabaiti, P. Schmuki, Semicond. Sci. Tech., 31 (2016) 014010-014017.

[19] N. F. Atta, H. M. A. Amin, M. W. Khalil, A. Galal, Int. J. Electrochem. Sci., 6 (2011) 3316-3332.

[20] L. Li, S. Chen, J. Kim, C. Xu, Y. Zhao, K.J. Ziegler, J. Cryst. Growth, 413 (2015) 31 36.

[21] A. Zaban, M. Greenshtein, J. Bisquert, ChemPhysChem, 4 (2003) 859-864.

[22] P. J. Cameron, L. M. Peter, S. Hore, J. Phys. Chem. B, 109 (2005) 930-936.

[23] H. S Han, J. S. Kim, D. H. Kim, G. S. Han, H. S. Jung, J. H. Noh, K. S. Hong 
Nanoscale 5 (2013), 3520-3526. 
List of Tables

Table 1: Photovoltaic properties of DSSCs with different nanowire lengths. ${ }^{\text {a) }}$ All $\mathrm{TiO}_{2}$ shells were annealed at $500{ }^{\circ} \mathrm{C}$ in air.

\begin{tabular}{llllll}
\hline & $\mathrm{V}_{\mathrm{oc}}(\mathrm{V})$ & $\begin{array}{l}\mathrm{J}_{\mathrm{sc}} \\
\left(\mathrm{mA} \cdot \mathrm{cm}^{-2}\right)\end{array}$ & $\mathrm{FF}(\%)$ & $\eta(\%)$ & $\begin{array}{l}\text { Dye loading } \\
\left(10^{-8} \mathrm{~mol} \cdot \mathrm{cm}^{-2}\right)\end{array}$ \\
\hline $20 \mu \mathrm{m}$ without $\mathrm{HfO}_{2}$ & $0.53 \pm 0.05$ & $9.94 \pm 0.08$ & $53.5 \pm 0.6$ & $2.81 \pm 0.05$ & $1.52 \pm 0.16$ \\
$10 \mu \mathrm{m}+\mathrm{HfO}_{2}$ & $0.72 \pm 0.04$ & $10.84 \pm 0.07$ & $55.2 \pm 0.8$ & $4.30 \pm 0.06$ & $0.94 \pm 0.11$ \\
$20 \mu \mathrm{m}+\mathrm{HfO}_{2}$ & $0.70 \pm 0.04$ & $12.14 \pm 0.04$ & $57.0 \pm 0.5$ & $4.85 \pm 0.07$ & $1.60 \pm 0.20$ \\
$28 \mu \mathrm{m}+\mathrm{HfO}_{2}$ & $0.70 \pm 0.06$ & $12.37 \pm 0.05$ & $53.2 \pm 0.7$ & $4.59 \pm 0.11$ & $2.21 \pm 0.17$ \\
\hline
\end{tabular}

a) Average values and standard deviations are based on 3-4 cells.

Table 2: Photovoltaic properties of DSSCs when the porous $\mathrm{TiO}_{2}$ shell was annealed between 400 and $600{ }^{\circ} \mathrm{C} .^{\text {a) }}$

\begin{tabular}{llllll}
\hline & $\mathrm{V}_{\mathrm{oc}}(\mathrm{V})$ & $\mathrm{J}_{\mathrm{sc}}\left(\mathrm{mA} \cdot \mathrm{cm}^{-2}\right)$ & $\mathrm{FF}(\%)$ & $\eta(\%)$ & $\begin{array}{l}\text { Dye loading } \\
\left(10^{-8} \mathrm{~mol} \cdot \mathrm{cm}^{-2}\right)\end{array}$ \\
\hline $400{ }^{\circ} \mathrm{C}$ & $0.69 \pm 0.04$ & $15.96 \pm 0.06$ & $50.6 \pm 0.8$ & $5.59 \pm 0.06$ & $2.28 \pm 0.18$ \\
$500^{\circ} \mathrm{C}$ & $0.70 \pm 0.04$ & $12.14 \pm 0.05$ & $57.0 \pm 0.5$ & $4.85 \pm 0.07$ & $1.60 \pm 0.20$ \\
$600^{\circ} \mathrm{C}$ & $0.70 \pm 0.03$ & $11.80 \pm 0.11$ & $50.3 \pm 0.5$ & $4.13 \pm 0.05$ & $1.24 \pm 0.15$
\end{tabular}

a) Average values and standard deviations are based on 3-4 cells. 
Figure captions

Figure 1: (a) A typical SEM image and (b) XRD pattern of as-grown ITO nanowires on the ITO/glass substrate.

Figure 2: TEM images of (a) as-grown ITO nanowires, (b) ITO nanowires coated with a $1.3 \mathrm{~nm} \mathrm{HfO} 2$ blocking layer by ALD, and (c) ITO nanowires coated with a porous $\mathrm{TiO}_{2}$ shell by $\mathrm{TiCl}_{4}$ treatment.

Figure 3: Current-voltage response of DSSCs fabricated with nanowires of different length (a) under AM 1.5 illumination and (b) dark conditions. All $\mathrm{TiO}_{2}$ shells were annealed at $500{ }^{\circ} \mathrm{C}$ in air.

Figure 4: (a) Open-circuit voltage decay (OCVD) curves and (b) corresponding electron lifetime of DSSCs fabricated with nanowires of different length. All $\mathrm{TiO}_{2}$ shells were annealed at $500{ }^{\circ} \mathrm{C}$ in air.

Figure 5: TEM images of the porous $\mathrm{TiO}_{2}$ shell surrounding ITO nanowires annealed at different temperatures: (a) 400, (b) 500, and (c) $600^{\circ} \mathrm{C}$. The red dotted lines indicate the boundaries of the $\mathrm{TiO}_{2}$ shell.

Figure 6: Current-voltage response of DSSCs when $\mathrm{TiO}_{2}$ was annealed between 400 and $600{ }^{\circ} \mathrm{C}$ under (a) AM 1.5 illumination and (b) dark conditions. 
List of schemes

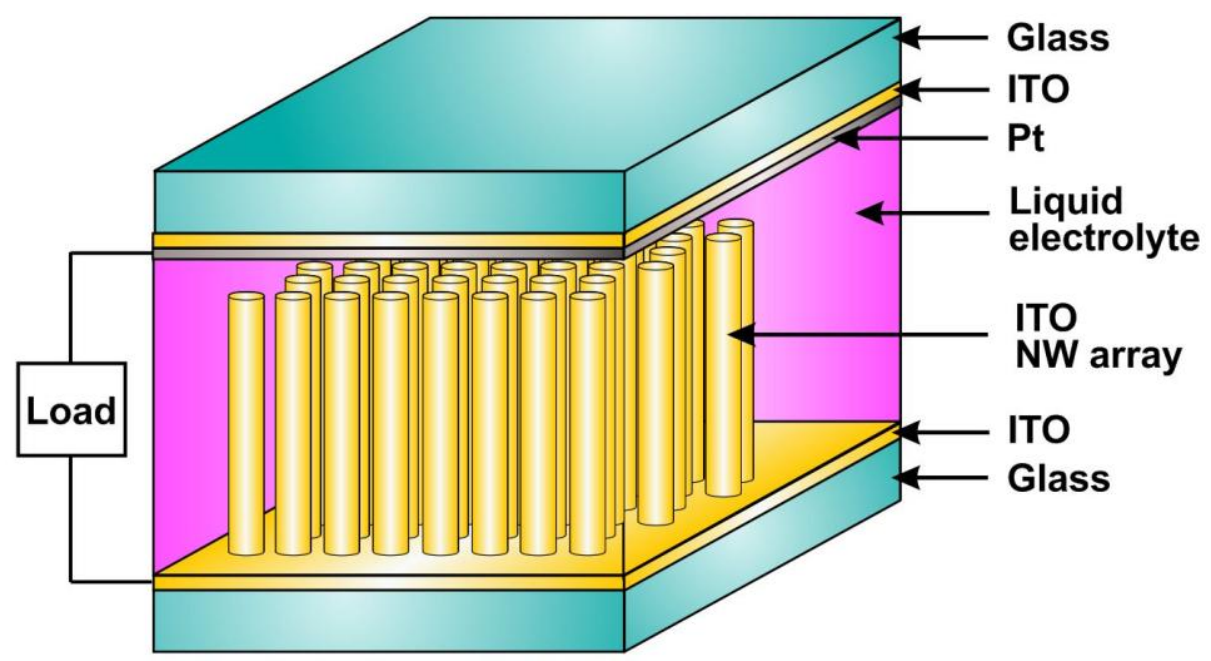

Scheme 1. Diagram showing the structure of a nanowire-based DSSC." 
Figure 1: (a) A typical SEM image and (b) XRD pattern of as-grown ITO nanowires on the ITO/glass substrate.
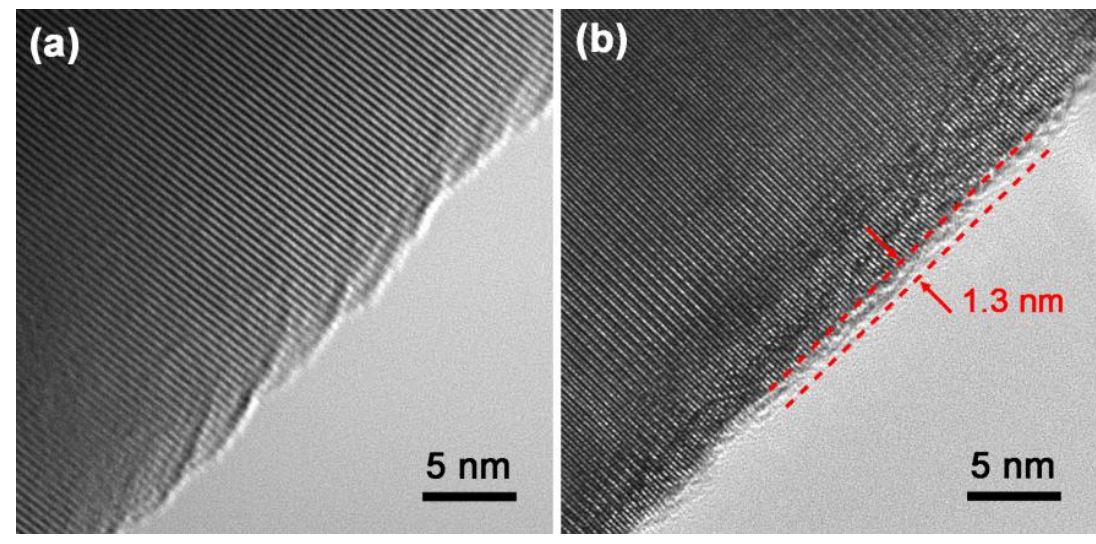

(c)

Figure 2: TEM images of (a) as-grown ITO nanowires, (b) ITO nanowires coated with a $1.3 \mathrm{~nm} \mathrm{HfO}$ blocking layer by ALD, and (c) ITO nanowires coated with a porous $\mathrm{TiO}_{2}$ shell by $\mathrm{TiCl}_{4}$ treatment. 


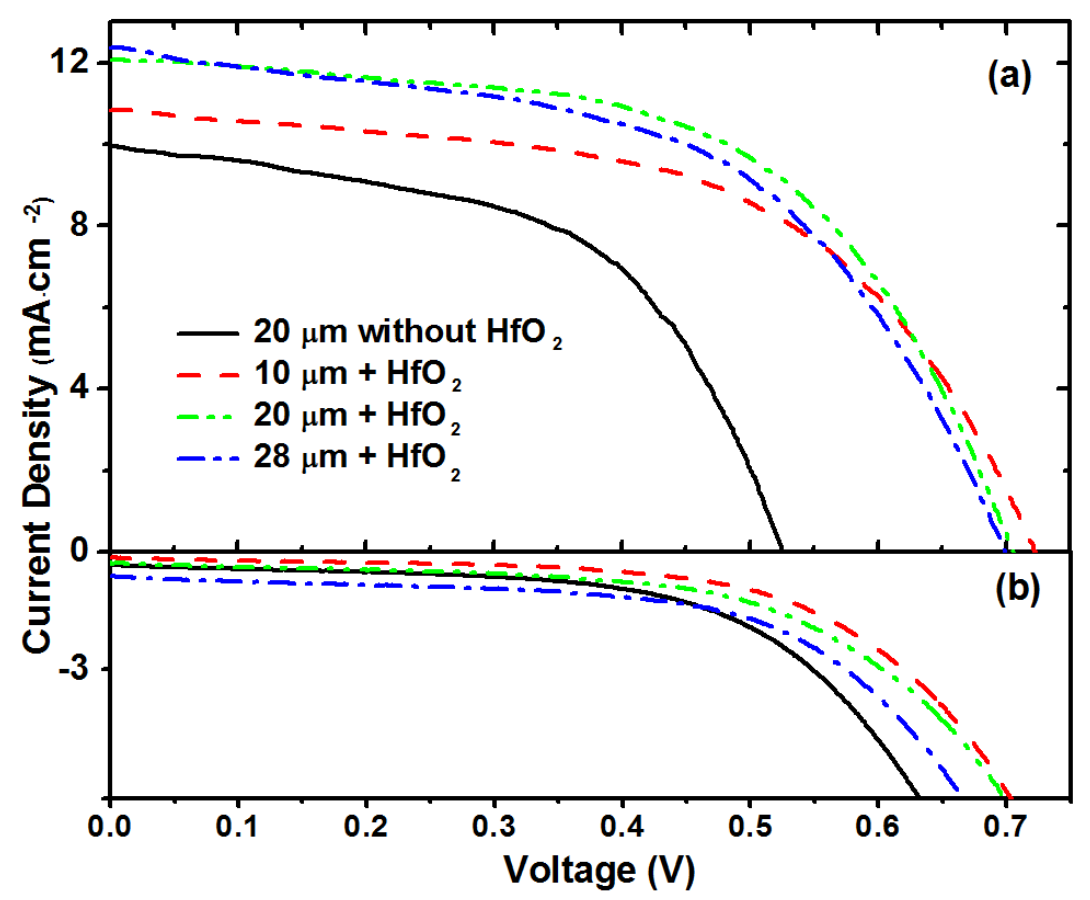

Figure 3: Current-voltage response of DSSCs fabricated with nanowires of different length (a) under AM 1.5 illumination and (b) dark conditions. All $\mathrm{TiO}_{2}$ shells were annealed at $500{ }^{\circ} \mathrm{C}$ in air.
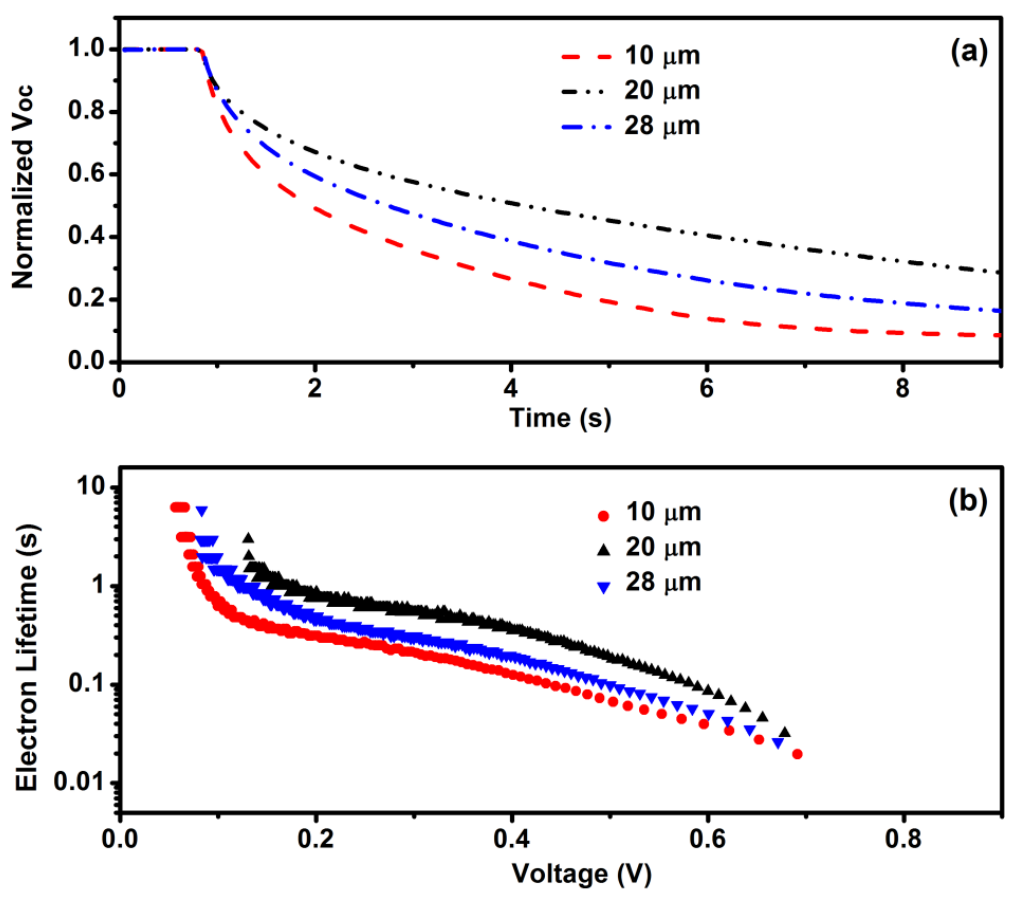

Figure 4: (a) Open-circuit voltage decay (OCVD) curves and (b) corresponding electron lifetime of DSSCs fabricated with nanowires of different length. $\mathrm{All}^{\mathrm{TiO}_{2}}$ shells were annealed at $500{ }^{\circ} \mathrm{C}$ in air. 


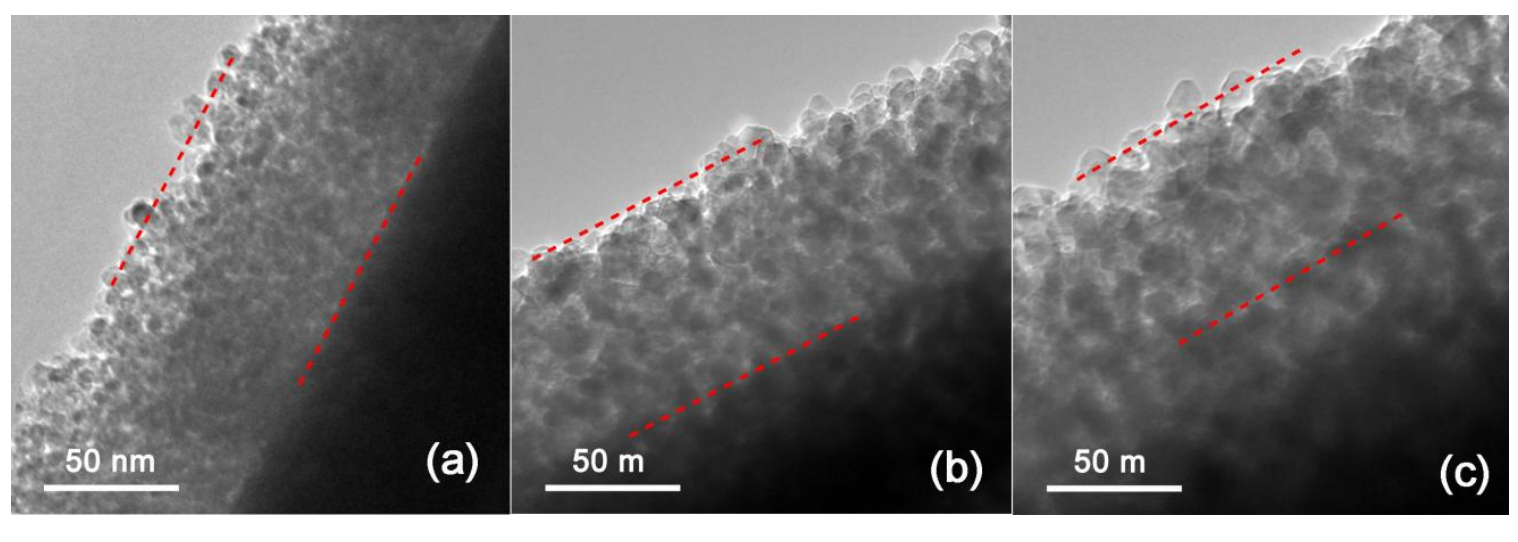

Figure 5: TEM images of the porous $\mathrm{TiO}_{2}$ shell surrounding ITO nanowires annealed at different temperatures: (a) 400 , (b) 500 , and (c) $600^{\circ} \mathrm{C}$. The red dotted lines indicate the boundaries of the $\mathrm{TiO}_{2}$ shell.

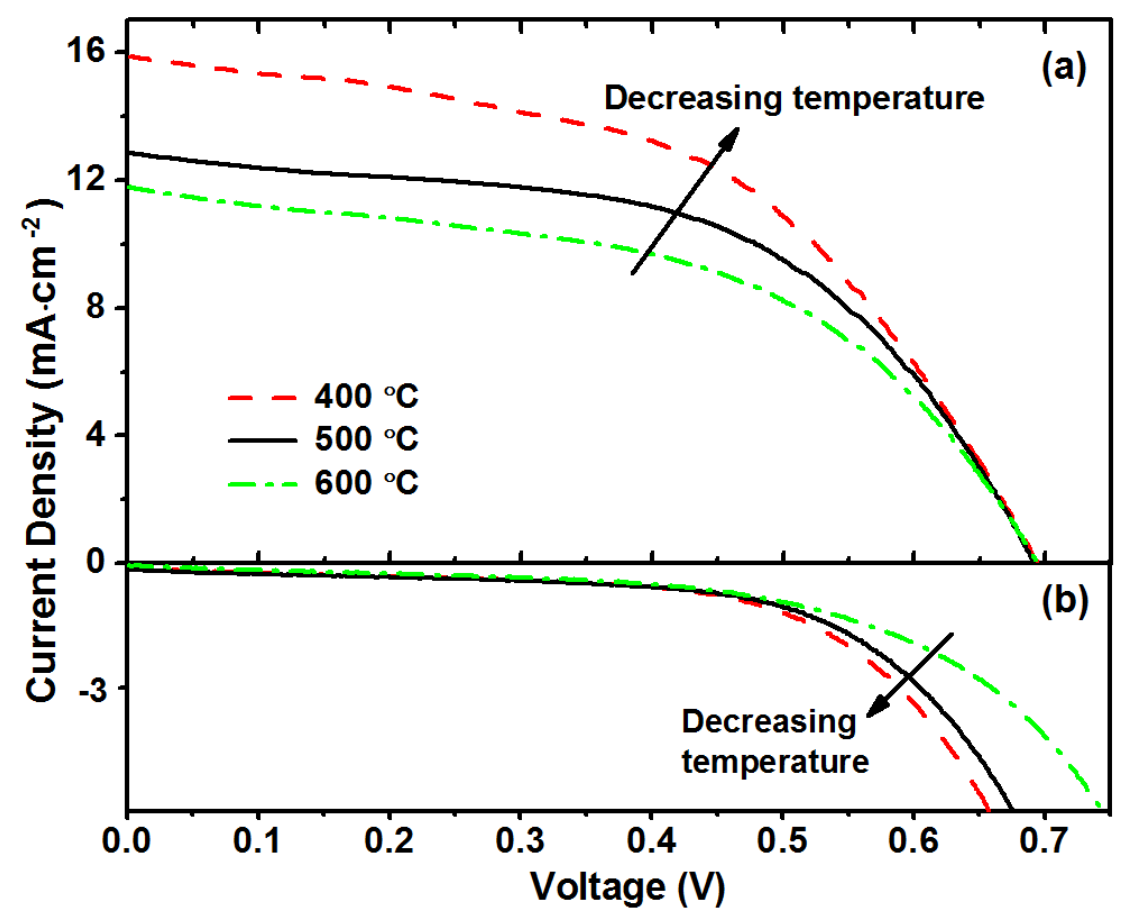

Figure 6: Current-voltage response of DSSCs when $\mathrm{TiO}_{2}$ was annealed between 400 and $600{ }^{\circ} \mathrm{C}$ under (a) AM 1.5 illumination and (b) dark conditions. 